\title{
Small Molecular Contaminant and
} Microorganism Can Be Simultaneously Detected Based on Nanobody-Phage: Using Carcinogen Aflatoxin and Its Main Fungal Aspergillus Section Flavi spp. in Stored Maize for Demonstration

OPEN ACCESS

Edited by:

Federica Giacometti,

University of Bologna, Italy

Reviewed by:

Shihua Wang,

Fujian Agriculture and Forestry

University, China

Sassan Rezaie,

Tehran University of Medical

Sciences, Iran

*Correspondence:

Qi Zhang

zhangqi01@caas.cn

Specialty section: This article was submitted to

Food Microbiology,

a section of the journal

Frontiers in Microbiology

Received: 12 October 2019 Accepted: 17 December 2019

Published: 23 January 2020

Citation:

Ren X, Yue X, Mwakinyali SE, Zhang W, Zhang Q and Li P (2020)

Small Molecular Contaminant

and Microorganism Can Be Simultaneously Detected Based on Nanobody-Phage: Using Carcinogen

Aflatoxin and Its Main Fungal

Aspergillus Section Flavi spp. in Stored Maize for Demonstration.

Front. Microbiol. 10:3023.

doi: 10.3389/fmicb.2019.03023

\begin{abstract}
Xianfeng Ren 1,2, Xiaofeng Yue ${ }^{1,2,3}$, Silivano Edson Mwakinyali1,2,3, Wen Zhang 1,2,3, Qi Zhang ${ }^{1,2,3 *}$ and Peiwu Li1,2,3,4,5

${ }^{1}$ Oil Crops Research Institute of the Chinese Academy of Agricultural Sciences, Wuhan, China, ${ }^{2}$ Key Laboratory of Detection for Mycotoxins, Ministry of Agriculture and Rural Affairs, Wuhan, China, ${ }^{3}$ Laboratory of Risk Assessment for Oilseeds Products, Ministry of Agriculture and Rural Affairs, Wuhan, China, ${ }^{4}$ Key Laboratory of Biology and Genetic Improvement of Oil Crops, Ministry of Agriculture and Rural Affairs, Wuhan, China, ${ }^{5}$ Quality Inspection and Test Center for Oilseeds Products, Ministry of Agriculture and Rural Affairs, Wuhan, China
\end{abstract}

Simultaneous detection technology has become a hot topic in analytical chemistry; however, very few reports on how to simultaneously detect small molecular contaminants and microorganisms have been in place. Aflatoxins are a group of highly toxic and carcinogenic compounds, which are produced mainly by Aspergillus flavus and Aspergillus parasiticus from section Flavi responsible for aflatoxin accumulation in stored cereals. Both aflatoxins and Aspergillus section Flavi were used to demonstrate the duplex real-time RCR method of simultaneously detecting small molecular contaminants and microorganisms. The detection of aflatoxins and Aspergillus section Flavi was carried out depending on the anti-idiotypic nanobody-phage $\mathrm{V}_{2-5}$ and aflatoxin-synthesis related gene nor-1 (=aflD), respectively. The quantitative standard curves for simultaneous detection of aflatoxins and Aspergillus section Flavi were constructed, with detection limits of $0.02 \mathrm{ng} / \mathrm{ml}$ and $8 \times 10^{2}$ spores $/ \mathrm{g}$, respectively. Naturally contaminated maize samples $(n=25)$ were analyzed for a further validation. The results were in good agreement between the new developed method and the referential methods (high-performance liquid chromatography and the conventional plating counts).

Keywords: real-time PCR, aflatoxin, Aspergillus, nanobody-phage, Nor-1 gene

\section{INTRODUCTION}

Simultaneous detection technology has been becoming a hot topic in analytical chemistry. Many methods have been reported for simultaneous detection of multi small molecular contaminants such as mycotoxins (Li et al., 2013, 2019; Zhang et al., 2016; Wang et al., 2017a), pesticide residues (Bagheri et al., 2016; Wang et al., 2017b), and 
veterinary drugs (Taranova et al., 2015; Dasenaki et al., 2016; Zhu et al., 2016). Also, a lot of methods were described for simultaneous detection of multi microorganisms such as pathogenic bacteria (Li et al., 2015; Yoo et al., 2015; VaisocherovaLisalova et al., 2016), fungal pathogens (Playford et al., 2006; Priyanka et al., 2015; Rahn et al., 2016), and even varied pathogens that belong to different kingdoms (Leber et al., 2016). However, very few reported on how to simultaneously detect small molecular contaminants and microorganisms. In many cases, small molecular contaminants and food-borne microorganisms may simultaneously occur in an identical sample. In this study, we developed a new method for simultaneous detection of aflatoxin and its major fungi in stored maize to demonstrate the potential to simultaneously detect small molecular contaminants and microorganisms.

Aflatoxins are highly toxic, carcinogenic, and mutagenic small molecular contaminants that can not only cause acute or chronic liver diseases but also seriously damage on other tissue organs (Eaton and Gallagher, 1994; Bennett and Klich, 2003). Aflatoxins $B_{1}, B_{2}, G_{1}$, and $G_{2}$ are the most frequent ones in agricultural products and the most toxic member whereby aflatoxin B1 has been classified as group I human carcinogen by the International Agency for Research on Cancer. In addition, main aflatoxigenic species, namely, A. flavus and A. parasiticus that belong to Aspergillus section Flavi (Giorni et al., 2007; Varga et al., 2011) are dominant in infection and colonization of agricultural crops (Desjardins, 2003). A. flavus is dominant in invading peanuts, corns, and cottons (Klich, 2007), while A. parasiticus contaminates broadly on cereals, oilseeds, spices, and nuts (Reddy et al., 2010). The contaminations triggered by A. flavus and A. parasiticus result in direct negative effects such as a reduction of production, a loss of nutrition and a diminution of market value, and aggravate environmental especially aqueous pollution and also pose serious threats to the health of animals and humans. The pathogenic Aspergillus spp. can cause avian aspergillosis and bovine mycotic abortion, and their spores are associated with human hypersensitivity pneumonitis (Gourama and Bullerman, 1995). Contaminations from aflatoxin and its producing molds usually occur concurrently, which increases a serious dangerousness for people's health as well as significantly reduces economic values of the host plants, agricultural products, feeds and/or foods.

Currently, a number of quantitative techniques for aflatoxin determination have been developed, mainly including High-Performance Liquid Chromatography (HPLC), Liquid Chromatography tandem Mass Spectrometry (LC-MS), rapid immune-chromatographic assays (ICA) and enzyme-linked immune sorbent assay (ELISA). Methods for quantifying Aspergillus section Flavi involved morphological and molecular technologies, the former of which need microbiologists who have a rich morphological knowledge to complete, whereas the latter have been widely used because of features of speediness, sensitivity, and accuracy. The present study developed a new method that realized a simultaneous run of two different types of PCR: (1) Display Mediated Immuno-polymerase Chain Reaction (PD-IPCR), which helps to determine total aflatoxins, and (2) a conventional real-time PCR (RT-PCR), which serves for determination of the main aflatoxin-producing fungi Aspergillus section Flavi in stored maize. Through the combination of the two PCRs, a new detection platform was developed, which makes it possible to simultaneously detect small molecular contaminants and microorganisms.

\section{MATERIALS AND METHODS}

\section{Materials}

The standard mycotoxin powders, the surfactants Tween-20, and the enzyme stabilizer bovine serum albumin (BSA) were obtained from Sigma-Aldrich (St. Louis, MO, United States). Escherichia coli ER2738 competent cells were purchased from Lucigen Corp. (Middleton, WI, United States). The Universal Probes Supermix was supplied by Bio-Rad (Hercules, CA, United States). DNA polymerase (iTaq), $\mathrm{Mg}^{2+}$, dNTPs, 6× loading buffer, and DNA marker were bought from Takara Bio (Beijing, China). All the other reagents used were of analytical grade or better.

The anti-aflatoxins monoclonal antibody 1C11 (mAb 1C11) and $\mathrm{V}_{2-5}$ phage displaying nanobody specific for $1 \mathrm{C} 11$ were produced by our team (Zhang et al., 2009; Wang et al., 2013b). A. flavus strain 3.4408 producing a high level of aflatoxins $B_{1}$ and $\mathrm{B}_{2}$ was used as a standard strain.

\section{Preparation of Phage for Small Molecular Contaminant Detection}

$\mathrm{V}_{2-5}$ phagemids, specific for $\mathrm{mAb} 1 \mathrm{C} 11$, previously transferred to E. coli ER2738 and stored at $-70^{\circ} \mathrm{C}$, need to be released and amplified from the E. coli, which was carried out as described in Lei et al. (2014). Finally, the phage particles were titrated by determining phage-forming unit (pfu) and stored at $-20^{\circ} \mathrm{C}$ as ready-to-use reagents to prepare additional supplies if needed.

\section{Preparation of Reference Gene for Microorganism Detection}

Nor-1 gene, catalyzing the transformation from norsolorinic to averantin, is the first key gene in the pathway of aflatoxins synthesis (Trail et al., 1994; Zhou and Linz, 1999). A. flavus strain 3.4408 was used to obtain nor-1 gene. After the inoculation on Czap ekDox Agar (CDA), the fungus was incubated at $28^{\circ} \mathrm{C}$ and $90 \%$ humidity for 7 days, and then the spores were washed down, counted using a hemocytometer counting chamber, and diluted into $50 \mathrm{ml}$ of potato dextrose broth (PDB) to a final concentration of $1 \times 10^{5}$ spores $/ \mathrm{ml}$, followed by a shaking at $180 \mathrm{rpm}$ for $96 \mathrm{~h}$ at $28^{\circ} \mathrm{C}$ using a Thermo Scientific MaxQ 4000 shaker (Danville, CA, United States). Finally, the mycelia were washed three times with double-distilled water, filtered through double-filter papers (Whatman \#4, Maidstone, United Kingdom), immediately freeze-dried and stored at $-70^{\circ} \mathrm{C}$ prior to DNA extraction.

DNA was extracted using DNeasy Plant Mini Kit (Qiagen, $\mathrm{GmbH}$, Germany) according to the manufacturer's introductions. After DNA extraction, a conventional PCR was performed essentially as described by Geisen (1996). The larger fragments 
(400 bp) of nor-1 gene were generated with primers: nor1F, 5' -ACCGCTACGCCGGCACTCTCGGCAC-3' and nor 1-R, 5' GTTGGCCGCCAGCTTCGACACTCCG-3'. Then, these larger fragments were purified using E.Z.N.A.TM Gel Extraction Kit (Omega Bio-Tek, Norcross, GA, United States) according to the manufacturer's protocols. Concentration of the purified products was determined by measuring the absorbance of samples at 260 and $280 \mathrm{~nm}$, using a NanoDrop 1000 (Thermo Fisher Scientific, Waltham, MA, United States), and the number of copies was calculated.

\section{Optimization of the Duplex Real-Time PCR}

The primer/probe systems are shown in Table 1. Ph-F, $\mathrm{R}$ primers, and $\mathrm{Ph}$-probe were designed according to the corresponding specific DNA sequences encoding anti-idiotypic nanobody $\left(\mathrm{V}_{2-5}\right)$ (Lei et al., 2014), while Tq-nor1-F, -R primers, and Tq-probe were designed according to the sequences of nor1 gene (Mayer et al., 2003a). The probes were labeled with non-fluorescent BHQ1 at the $3^{\prime}$-end and with reporter dyes of FAM or Hex at the $5^{\prime}$-end. Primer Premier 6.0 (Premier Biosoft International, Palo Alto, CA, United States) was used to ensure the compatibility of primers and probes.

A CFX96 ${ }^{\mathrm{TM}}$ real-time PCR system (Bio-Rad, Hercules, CA, United States) was used to perform the real-time PCR assay. The duplex real-time PCR consisted of two single-plex amplification systems that separately used $\mathrm{V}_{2-5}$ phage DNA and nor-1 gene as templates. After the separate optimization, the two single-plex PCRs were combined to form a duplex real-time PCR, with an additional 0.25-1.0 U DNA polymerase (iTaq), $\mathrm{Mg}^{+2}$ (1-2 mM), and dNTPs $(200-400 \mu \mathrm{M})$.

Parameters for the optimized system were as follows: $V_{2-5}$ phage $(2 \mu \mathrm{l})$ and nor-1 $(1 \mu \mathrm{l})$ were mixed with the PCR working solution containing two primer/probe systems (Table 1), iTaq Universal Probes Supermix (5 $\mu \mathrm{l})$, an additional iTaq $(0.75 \mathrm{U})$, $\mathrm{MgCl}_{2}(2 \mathrm{mM})$, and dNTPs $(400 \mu \mathrm{M})$. Double-distilled water was added to make up the total volume to $10 \mu \mathrm{l}$. After an initial denaturation at $95^{\circ} \mathrm{C}$ for $5 \mathrm{~min}, 40$ cycles were at $95^{\circ} \mathrm{C}$ for $10 \mathrm{~s}$ and $60^{\circ} \mathrm{C}$ for $30 \mathrm{~s}$. No template control was used to verify the quality of amplification. All the assays were carried out in triplicate.

To evaluate the amplification efficiency (E), $V_{2-5}$ phage particles were diluted in PBS buffer $(10 \mathrm{mM}$ sodium phosphate buffer containing $137 \mathrm{mM} \mathrm{NaCl}$ and $2.68 \mathrm{mM} \mathrm{KCl}, \mathrm{pH} \mathrm{7.4)}$ to a series of final concentrations ranging from $10^{9}$ to $10^{2}$ $\mathrm{pfu} / \mathrm{ml}$. The reference nor-1 gene was 10 -fold serially diluted in nuclease-free $\mathrm{H}_{2} \mathrm{O}$ to final concentrations of $10^{8}-10^{1}$ copies $/ \mu \mathrm{l}$. $\mathrm{Ct}$ values, corresponding to each dilution, were automatically calculated by the instrument. The efficiency was calculated based on: $E=\left[10^{1 /- \text { slope }}-1\right] \times 100 \%$, by using logarithm of templates as abscissa and $\mathrm{Ct}$ values as ordinate to plot amplification calibration curves.

\section{Immunoreaction for Small Molecular Contaminant Detection}

A polystyrene microtiter plate (96-well) was coated with $1.0 \mu \mathrm{g} / \mathrm{ml} \mathrm{mAb} 1 \mathrm{C} 11$ at $37^{\circ} \mathrm{C}$ for $1 \mathrm{~h}$. Then, the plate was washed with PBST [PBS containing $0.05 \%(\mathrm{v} / \mathrm{v})$ Tween 20] three times and, then, blocked with a buffer [PBST containing 3\% (w/v) skimmed milk] at $37^{\circ} \mathrm{C}$ for $45 \mathrm{~min}$. The plate was washed three times. Then, the mixture $(100 \mu \mathrm{l})$ containing $50 \mu \mathrm{l}$ of $\mathrm{V}_{2-5}$ phages $\left(1.0 \times 10^{10} \mathrm{pfu} / \mathrm{ml}\right)$ and the same volume of aflatoxins solution were added into each micro-plate well. After the incubation at $37^{\circ} \mathrm{C}$ for $1 \mathrm{~h}$, the plate was washed with PBST 10 times. Subsequently, the $\mathrm{V}_{2-5}$ phages captured by mAb $1 \mathrm{C} 11$ at the bottom of the plate were eluted by Glycine/HCl buffer $(100 \mu \mathrm{l}$, $0.2 \mathrm{M}, \mathrm{pH} 2.1$, containing $1 \% \mathrm{BSA}$ ) at $37^{\circ} \mathrm{C}$ for $15 \mathrm{~min}$. Then, the eluent containing the released phages was neutralized using $1 \mathrm{M}$ Tris-base buffer ( $\mathrm{pH}$ 9.1).

Aflatoxins $B_{1}, B_{2}, G_{1}$, and $G_{2}$ occur in natural samples at different ratios (Kensler et al., 2011). According to their frequencies of occurrence in natural samples, standards $\left(B_{1}: B_{2}\right.$ : $\left.\mathrm{G}_{1}: \mathrm{G}_{2}=1.0: 0.1: 0.3: 0.03, \mathrm{w} / \mathrm{w} / \mathrm{w} / \mathrm{w}\right)$ used for total aflatoxin determination were prepared. The standard was threefold serially diluted at serial concentrations $(33.3 \mathrm{ng} / \mathrm{ml}$ to $1.69 \mathrm{pg} / \mathrm{ml})$. After the immunoreaction as described above, the eluted $\mathrm{V}_{2-5}$ phages solution $(2 \mu \mathrm{l})$ was used for the duplex real-time PCR system. The standard curve was constructed by plotting Ct values versus Log total aflatoxin concentrations $(\log 10)$ by four parameter logistic regression.

\section{Isolation of DNA From Maize Samples}

Ten grams of maize was finely milled into particles $<500 \mu \mathrm{m}$ diameter using a laboratory mill. Subsequently, $0.2 \mathrm{~g}$ of the powder was precisely weighed, transferred into a nuclease-free tube, and smashed using an automatic fast-grinding apparatus Tissuelyser-48 (Jingxin Science, Shanghai, China), in the presence of $200 \mu \mathrm{l}$ of CTAB (hexadecyltrimethyl ammonium bromide) buffer [20 g/L CTAB, 0.1 M Tris- $\mathrm{HCl}(\mathrm{pH}=8.0), 20 \mathrm{mM}$ EDTA $(\mathrm{pH}=8.0)$ and $1.4 \mathrm{M} \mathrm{NaCl}$ ) and two steel beads $(1.5 \mathrm{~mm}$ diameter). Then, an additional $1.6 \mathrm{ml}$ of CTAB buffer was added

TABLE 1 | Primer and probe systems used in the duplex real-time PCR system.

\begin{tabular}{|c|c|c|c|c|c|}
\hline Primer/probe & Sequence $\left(5^{\prime}\right.$ to $\left.3^{\prime}\right)$ & $T_{\mathrm{m}}\left({ }^{\circ} \mathrm{C}\right)$ & Amplicon (bp) & Working concentration $(\mu \mathrm{M})$ & Target gene \\
\hline $\mathrm{Ph}-\mathrm{F}$ & GTGGTAGCACAAACTATG & 49.5 & 131 & 0.3 & Phage DNA \\
\hline $\mathrm{Ph}-\mathrm{R}$ & GGCTGCACAGTAATAAAC & 50.2 & & 0.3 & \\
\hline Ph- probe & FAM-CCGATTCACCATCTCCAGAGACA-BHQ1 & 58.2 & & 0.4 & \\
\hline Tq-nor1-F & GTCCAAGCAACAGGCCAAGT & 57.4 & 66 & 0.2 & Nor-1 gene \\
\hline Tq-nor1-R & TCGTGCATGTTGGTGATGGT & 55.4 & & 0.2 & \\
\hline Tq-probe & HEX-TGTCTTGATCGGCGCCCG-BHQ1 & 62.2 & & 0.3 & \\
\hline
\end{tabular}


into the tube and immediately incubated in a water bath at $63^{\circ} \mathrm{C}$ for $2 \mathrm{~h}$. Then, 1 volume of phenol:chloroform:isoamyl alcohol (v:v:v, 25:24:1) was added, gently mixed, and centrifuged at $15,000 \mathrm{~g}$ for $10 \mathrm{~min}$. After the recovery of the aqueous phase, 1 volume of chloroform:isoamyl alcohol (v:v = 24:1) was added, homogenized, and centrifuged again. The aqueous phase was recovered and 1 volume of chloroform was added. After the centrifugation at $15,000 \mathrm{~g}$ for $10 \mathrm{~min}$, the aqueous phase was recovered again, followed by an addition of 0.6 volume of isopropyl alcohol (pre-cooled at $-20^{\circ} \mathrm{C}$ for $2 \mathrm{~h}$ ). After the centrifugation at $15,000 \mathrm{~g}$ for $15 \mathrm{~min}$, the aqueous phase was discarded. The DNA was cleaned with $70 \%$ alcohol, suspended in $70 \mu \mathrm{l}$ of nuclease-free $\mathrm{H}_{2} \mathrm{O}$, and stored at $-20^{\circ} \mathrm{C}$.

To generate a standard curve for Aspergillus section Flavi determination, $0.2 \mathrm{~g}$ of the finely milled blank-maize powder was precisely weighed, transferred into a nuclease-free tube, and inoculated with $200-\mu \mathrm{l}$ spores (obtained from 6-day-old A. flavus strain 3.4408 ) to final concentrations of $8 \times 10^{2}$ to $8 \times 10^{8}$ spores/g. After incubation at $28^{\circ} \mathrm{C}$ for $1 \mathrm{~h}$, samples were used to extract DNA as described above. DNA products $(1 \mu l)$ were used as templates for the duplex real-time PCR system. Log spores/g was used as abscissa and the corresponding Ct values were used as ordinate to plot the standard curve.

\section{Samples Analysis and Validation}

The blank maize samples were purchased at a local market and verified as blank using HPLC and conventional plating counts. The naturally contaminated maize samples $(n=25)$ were gathered from Shandong province of China. Samples (10 g) were finely milled into particles $<500 \mu \mathrm{m}$ diameter, $0.2 \mathrm{~g}$ of which was used to extract DNA for Aspergillus section Flavi determination. For aflatoxin extraction, $5.0 \mathrm{~g}$ of the milled samples was treated with $15 \mathrm{ml}$ of methanol:water (70:30, v/v) under a shaking condition at $250 \mathrm{rpm}$ for $1 \mathrm{~h}$. After a centrifugation $(5000 \mathrm{~g}$ for $10 \mathrm{~min}$ at $4^{\circ} \mathrm{C}$ ), samples were filtered with double-filter papers (Whatman \#4, Maidstone, United Kingdom) and diluted sevenfold with $4 \% \mathrm{BSA} / \mathrm{PBS}(\mathrm{w} / \mathrm{v})$. Dilutions were used directly in the Section "Immunoreaction for Small Molecular Contaminant Detection." After the immunoreaction and DNA extraction, the eluted phages DNA and DNA products extracted from maize samples were amplified simultaneously in the optimized duplex real-time PCR system. Ct values were associated to standard curves to calculate concentrations of aflatoxins and aflatoxigenic fungi.

A validation involved testing of 25 naturally contaminated maize samples, using the newly developed method and the gold standard reference methods (HPLC and conventional plating counts) in parallel. HPLC was carried out as described in Ren et al. (2019). For determination of Aspergillus section Flavi density by conventional plating counts, colony-forming units (CFUs) were determined using dichloran rose bengal chloramphenicol agar (DRBC) supplemented with $1 \% \mathrm{NaCl}$ (Passone et al., 2010).

\section{Statistical Analysis}

For aflatoxin determination, $\mathrm{IC}_{10}, \mathrm{IC}_{50}$ (half-maximal inhibition), and $\mathrm{IC}_{20}-\mathrm{IC}_{80}$ were used to calculate the limit of detection (LOD), sensitivity and linear range, respectively. The statistical analysis and plotting were performed using Microsoft Excel 2007 and OriginPro 9.0 (OriginLab Corporation, Northampton, MA, United States). To assess matrix effects, data were compared according to Student $t$-test using Graph PadInstat 3.0 (GraphPad Software, San Diego, CA, United States).

\section{RESULTS AND DISCUSSION}

\section{Optimization of the Duplex Real-Time PCR}

At first, two single-plex real-time PCR systems were directly combined without any further optimization. As shown in Figure 1A, Ct values corresponding to $\mathrm{V}_{2-5}$ phages were much higher, which indicated that the amplification of phage DNA was extremely inhibited, whereas the additional $\mathrm{Mg}^{+2}$, dNTPs (Figure 1B), and DNA polymerase (iTaq) (Figure 1C) enhanced phage DNA amplification with significantly lower Ct values. Principles defining optimal parameters were intended to ensure that positive $\mathrm{Ct}$ values are lower, because the lower $\mathrm{Ct}$ values ensured a wider linear range and a lower limit of the detection. Thus, the additional $2 \mathrm{mM} \mathrm{MgCl}_{2}, 400 \mu \mathrm{M}$ dNTPs, and $0.75 \mathrm{U}$ iTaq were selected as the optimal conditions. These results suggest that insufficient DNA polymerase, $\mathrm{Mg}^{+2}$, and/or nucleotides can inhibit the amplification of lowabundance templates, which was in accordance with the conclusion of Svec et al. (2015).

\section{Efficiency Assessment of the Duplex Real-Time PCR}

Amplification data are shown in Figures 2A,C. For $\mathrm{V}_{2-5}$ phage and reference nor-1 gene, the resulting slopes for linear fit were -3.37 (Figure 2B) and -3.56 (Figure 2D), respectively. Thus, amplification efficiencies were calculated as 98 and $91 \%$, with the lowest detectable concentrations of $10^{3} \mathrm{pfu} / \mathrm{ml} \mathrm{V}_{2-5}$ and $10^{2}$ copies/ $\mu 1$ nor-1, indicating that the optimized duplex realtime PCR was accurate enough for simultaneous quantification of the both targets.

\section{Matrix Effect, Sensitivity, and Specificity for Total Aflatoxin Determination}

To assess matrix effects on total aflatoxin determination, $5 \mathrm{~g}$ of blank maize samples were treated with $15 \mathrm{ml}$ of methanol/PBS (70:30, v/v) under a shaking condition (250 rpm for $1 \mathrm{~h}$ ), centrifuged at $5000 \mathrm{~g}$ for $10 \mathrm{~min}$, and filtered through doublefilter paper, and then the supernatants were diluted sevenfold with distilled-water. Subsequently, total aflatoxin standard was diluted into $10 \%$ methanol/PBS (10:90, v/v) buffer and the dilutions of maize extracts to a final concentration of $33.3 \mathrm{ng} / \mathrm{ml}$ to $1.69 \mathrm{pg} / \mathrm{ml}$. Maximal and minimal $\mathrm{Ct}$ values were obtained at $33.3 \mathrm{ng} / \mathrm{ml}$ and $1.69 \mathrm{pg} / \mathrm{ml}$, respectively. As shown in Figure 3A, $\Delta \mathrm{Ct}$ (=Maximal $\mathrm{Ct}$ - Minimal $\mathrm{Ct}$ ) had a significant difference $(P<0.001$, according to the Student $t$-test) between $10 \%$ methanol/PBS buffer $(\Delta \mathrm{Ct}=10.8)$ and maize extracts 

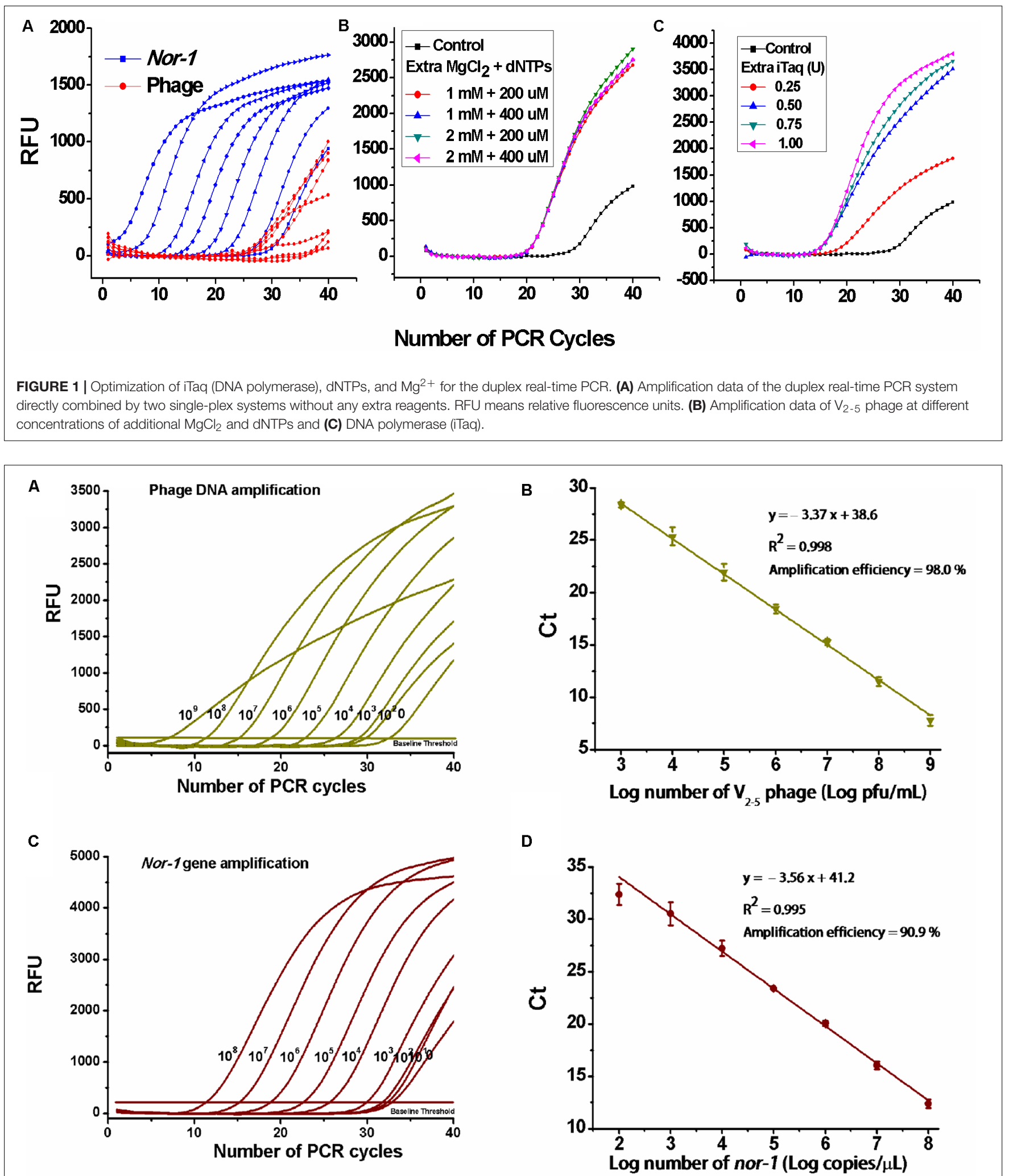

FIGURE 2 | Determination of amplification efficiency of the real-time PCR. (A) PCR amplification for 10-fold serial dilutions of $V_{2-5}$ phage particles $\left(10^{9}, \ldots 10^{8}, \ldots 10^{7}, \ldots 10^{6}, \ldots 10^{5}, \ldots 10^{4}, \ldots 10^{3}, \ldots 10^{2} \mathrm{pfu} / \mathrm{ml}\right)$ and (C) reference nor -1 gene $\left(10^{8}, \ldots 10^{7}, \ldots 10^{6}, \ldots 10^{5}, \ldots 10^{4}, \ldots 10^{3}, \ldots 10^{2}, \ldots 10^{1} \mathrm{copies} / \mathrm{\mu l}\right) . \mathrm{RFU}$ means relative fluorescence units. (B) Standard curve of amplification efficiency for $V_{2-5}$ phage and (D) reference nor- 1 gene. Each data point is the average of three independent measurements. 

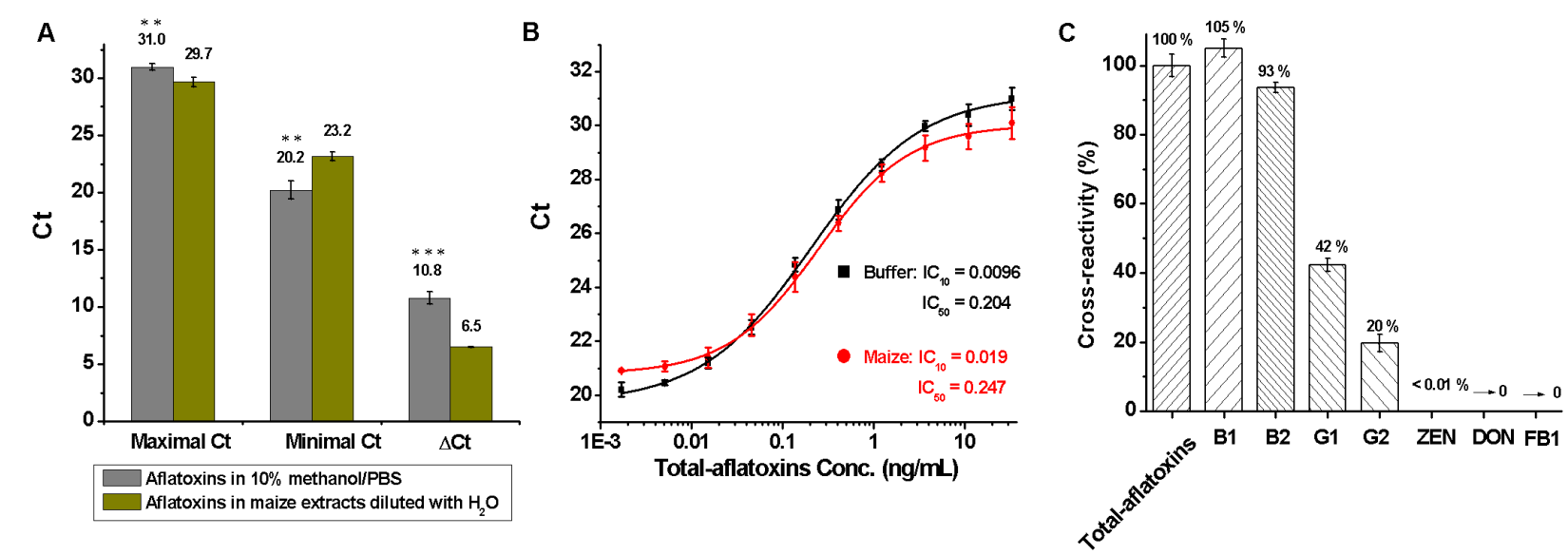

FIGURE 3 | Evaluation of the duplex real-time PCR for total aflatoxins detection. (A) Analysis of matrix effects, by comparing the difference of maximal, minimal, and $\Delta$ Ct values between $10 \%$ methanol/PBS buffer and maize extracts that diluted with water; ${ }^{* * *} P<0.001,{ }^{* *} P<0.01$, ${ }^{*} P<0.05$ according to the Student $t$-test. (B) Standard curves for total aflatoxins in 10\% methanol/PBS buffer (black) and maize extracts (red) after the elimination of matrix interference with 4\% BSA/PBS $(w / v)$; conc. is the abbreviation for concentration. (C) Cross-reactivity (CR) for mycotoxins including total aflatoxins, $B_{1}, B_{2}, G_{1}, G_{2}, z^{2} a_{2}$ lenone (ZEN), deoxynivalenol (DON), and fumonisin $\mathrm{B}_{1}\left(\mathrm{FB}_{1}\right)$.

$(\Delta \mathrm{Ct}=6.5)$, meaning maize matrix had a significant effect on total aflatoxin detection.

To eliminate matrix effects, the maize extracts were diluted sevenfold with $4 \%$ BSA/PBS (w/v), which essentially eliminated the matrix interference. Standard curves for total aflatoxins in $10 \%$ methanol/PBS buffer and maize extracts that were diluted with BSA/PBS (w/v) are shown in Figure 3B. The LOD, sensitivity, and linear range of the method for total aflatoxins in maize were $0.02,0.25$, and $0.05-1.21 \mathrm{ng} / \mathrm{ml}$, respectively. The LOD was much lower than that of immune-chromatographic assays (Li et al., 2013), immunochip (Wang et al., 2012), and HPLC methods (Khayoon et al., 2010) reported previously.

During assessment of specificity, the cross-reactivity (CR) for common mycotoxins was tested and calculated as: $\%$ $\mathrm{CR}=\left(\mathrm{IC}_{50 \text { Total }}\right.$ aflatoxins $\left./ \mathrm{IC}_{50 \text { analyte }}\right) \times 100$. As shown in Figure 3C, higher cross-reactivity against total aflatoxins (100\%) and aflatoxins $\mathrm{B}_{1}(105 \%)$ and $\mathrm{B}_{2}(93 \%)$, lower cross-reactivity toward aflatoxins $\mathrm{G}_{1}(42 \%)$ and $\mathrm{G}_{2}(20 \%)$, and no cross-reactivity with zearalenone (ZEN), deoxynivalenol (DON), and fumonisin $\mathrm{B}_{1}\left(\mathrm{FB}_{1}\right)$ were obtained, indicating that the method was specific for aflatoxins $B_{1}, B_{2}, G_{1}$, and $G_{2}$.

\section{Matrix Effect, Sensitivity, and Specificity for Aspergillus Section Flavi Determination}

On assessment of matrix effects on Aspergillus section Flavi determination, spores were diluted in water or inoculated in maize to serial concentrations of $8 \times 10^{2}$ to $8 \times 10^{8}$ spores $/ \mathrm{ml}$ or spores/g. As shown in Figure 4A, maximal, minimal, and $\Delta \mathrm{Ct}$ values had no differences between spores inoculated in maize and in water, indicating no matrix effects. Due to the complexity of food samples, food matrices-associated inhibitors such as protein, polysaccharide, and oleic acid usually interfere with the activities of enzymes and, subsequently, reduce the detection sensitivity
(Wilson, 1997; Hanna et al., 2005). Fortunately, no matrix inhibition was discovered in this experiment, probably because of the use of phenol and chloroform during the extraction of DNA, which could not only remove proteins but also eliminate other matrix inhibitors.

Amplification data of A. flavus spores that were 10-fold serially diluted in maize are shown in Figure 4B. The standard curve for mold detection is shown in Figure 4C. A good linear relationship between $\mathrm{Ct}$ values and spore numbers was obtained, with detective standard curve: $y=-2.03 x+38.8$ and $R^{2}=0.98$. As shown in Figures $4 \mathbf{B}, \mathbf{C}$, the linear range for $A$. flavus detection was $8 \times 10^{2}$ to $8 \times 10^{8}$ spores/g, with the lowest detectable concentration of $8 \times 10^{2}$ spores $/ g$.

The specificity of the primer/probe set of nor-1 has been already demonstrated, using the purified genomic DNA of different food-related fungi (Mayer et al., 2003a; Iheanacho et al., 2014). Their studies showed that A. flavus and A. parasiticus gave positive results, whereas other tested strains such as different Aspergillus spp., Penicillium spp., and Fusarium spp. gave negative results. In our study, the specificity was also tested using strains commonly occurred in maize. As expected, A. parasiticus $(n=3)$ and $A$. flavus $(n=4$, including two aflatoxin non-producing strains) gave PCR amplifications similar to that of A. flavus strain 3.4408 (data not shown), indicating that the new method could detect $A$. parasiticus and $A$. flavus including aflatoxin producing and non-producing strains, whereas no PCR amplifications were detected for the other tested strains (Aspergillus niger, Aspergillus nidulans, Penicillium oxalicum, Fusarium moniliforme, Fusarium nivale, Alternaria alternate, Trichoderma harzianum, and Rhizopus nigricans).

Regarding nor-1 gene as a biomarker for A. flavus and A. parasiticus detection has been demonstrated for several times. Mayer et al. (2003b) demonstrated that the tendency of nor1 gene copies was the same as that of A. flavus CFUs in wheat with the prolonged incubation time (Mayer et al., 2003b). 

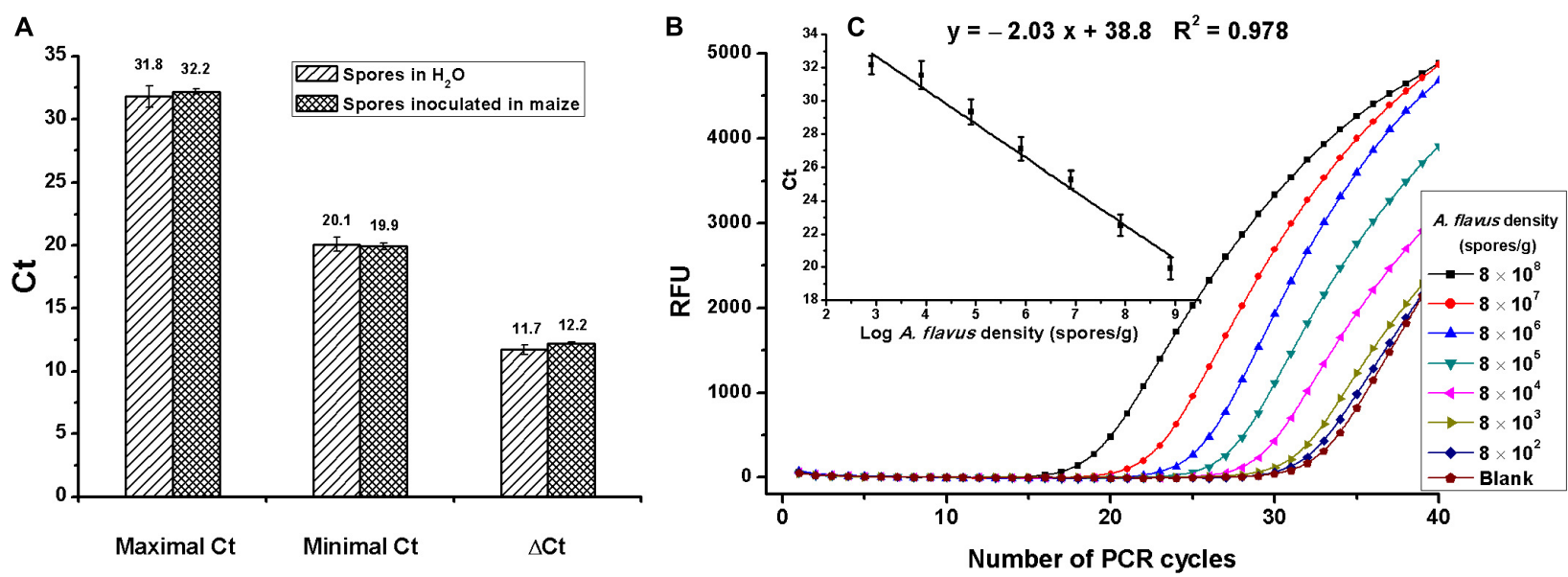

FIGURE 4 | Evaluation of the duplex real-time PCR for Aspergillus section Flavi determination. (A) Analysis of matrix effects, by comparing the difference of maximal, minimal, and $\Delta$ Ct values between assays that spores diluted in water or inoculated in maize; no difference was found, according to the Student $t$-test.

(B) Amplification data for serial concentrations of $A$. flavus spores inoculated in maize $\left(8 \times 10^{8}, \ldots 8 \times 10^{7}, \ldots 8 \times 10^{6}, \ldots 8 \times 10^{5}, \ldots 8 \times 10^{4}, \ldots 8 \times 10^{3}, \ldots 8 \times 10^{2}\right.$ spores/g). RFU means relative fluorescence units. (C) Standard curves constructed for Aspergillus section Flavi detection in maize with detection linear range of $8 \times 10^{2}$ to $8 \times 10^{8}$ spores $/ g$.

Additionally, nor-1 copies were demonstrated to be correlated to CFUs of A. flavus in pepper, maize, and paprika (Bagnara et al., 2000; Mayer et al., 2003a). Passone et al. (2010) also developed an analytical method determining Aspergillus section Flavi based on nor-1 gene and demonstrated a good correlation $(r=0.613$; $P<0.0001)$ between nor- 1 copies and CFUs in naturally stored peanut. These results indicated that the PCR system based on nor1 gene was specific and accurate for A. flavus and A. parasiticus determination, which was in accordance with our finding.

At present, some other methods based on PCRs have also been established to detect aflatoxigenic fungi in agricultural products. For example, an analytical method determining CFU values of Aspergillus section Flavi in stored peanut samples was established, with a detection linear range of $2.5 \times 10^{3}$ to $10^{7} \mathrm{cfu} / \mathrm{g}$ (Passone et al., 2010), a lower sensitivity compared with that of our method. The method based on omt-1 gene was also proposed to quantify aflatoxin-producing molds, over the range 4 to $1 \mathrm{log}$ cfu/g (Rodriguez et al., 2012). Since mycelial fragments consist of many multinucleate cells (Jennings and Lysek, 1996; Kaminskyj and Hamer, 1998), but give only one colony in a plate, CFU values could not mirror the real density of Aspergillus section Flavi in samples. Thus, our new method, based on the detection of spores, was more sensitive and accurate.

\section{Recovery of Total Aflatoxins and}

\section{A. flavus Spores}

To test the recovery, blank maize samples (10 g) were spiked with total aflatoxin standard (10, 100, and $200 \mu \mathrm{g} / \mathrm{kg})$ and simultaneously inoculated with fresh spores of $A$. flavus 3.4408 (3, 5, and 8 Log spores/g). Assays were carried out in triplicate on the same day for intra-assay precision evaluation and in five different days for inter-assay precision evaluation. Recoveries for aflatoxins and A. flavus spores were $84-111 \%$ and $94-107 \%$, respectively, with variable coefficients (CVs) of $0.47-11.2 \%$ (Table 2 ), indicating a good repeatability and reproducibility of the method.

\section{Validation}

The testing results of 25 natural samples and correlations of the results obtained by different methods are shown in Table 3 and Figure 5. For total aflatoxin determination, results of the new method and HPLC had a good correlation, with a linear regression equation: $y=0.97 x-4.31$ and $R^{2}=0.99$; for Aspergillus section Flavi, validation results were also in good

TABLE 2 | Recovery of total aflatoxins and A. flavus in maize by the duplex real-time PCR analysis.

\begin{tabular}{|c|c|c|c|c|c|}
\hline Assay & Analyte & $\begin{array}{c}\text { Spiked } \\
\text { level }\end{array}$ & $\begin{array}{c}\text { Recovered } \\
\text { level } \pm \text { SD }\end{array}$ & $\begin{array}{c}\text { Recovery } \\
\text { (\%) }\end{array}$ & $\begin{array}{l}\text { CV } \\
(\%)\end{array}$ \\
\hline Intra-assay & Total aflatoxins & 10 & $8.84 \pm 0.30$ & 88.4 & 3.43 \\
\hline \multirow[t]{5}{*}{$(n=3)^{\mathrm{a}}$} & $(\mu \mathrm{g} / \mathrm{kg})$ & 100 & $92.1 \pm 6.12$ & 92.1 & 6.65 \\
\hline & & 200 & $206 \pm 5.50$ & 103 & 2.67 \\
\hline & A. flavus & 3 & $2.83 \pm 0.24$ & 94.4 & 8.59 \\
\hline & (log spores/g) & 5 & $5.10 \pm 0.36$ & 102 & 6.70 \\
\hline & & 8 & $8.57 \pm 0.37$ & 107 & 4.29 \\
\hline Interassay & Total aflatoxins & 10 & $8.39 \pm 0.04$ & 83.9 & 0.47 \\
\hline \multirow[t]{5}{*}{$(n=5)^{b}$} & $(\mu \mathrm{g} / \mathrm{kg})$ & 100 & $43.9 \pm 1.29$ & 87.8 & 2.94 \\
\hline & & 200 & $111 \pm 3.57$ & 111 & 3.23 \\
\hline & A. flavus & 3 & $3.04 \pm 0.34$ & 101 & 11.2 \\
\hline & (log spores/g) & 5 & $4.89 \pm 0.30$ & 97.8 & 6.13 \\
\hline & & 8 & $8.15 \pm 0.38$ & 102 & 4.60 \\
\hline
\end{tabular}

aEach assay was carried out in triplicate on the same day. ${ }^{b}$ The interassay was carried out in five different days. 
TABLE 3 | Comparison of results obtained by the duplex real-time PCR and referential methods for total aflatoxins and Aspergillus section Flavi detection in naturally contaminated maize.

\begin{tabular}{|c|c|c|c|c|}
\hline \multirow[t]{2}{*}{$\begin{array}{l}\text { Maize } \\
\text { sample }\end{array}$} & \multicolumn{2}{|c|}{$\begin{array}{l}\text { Total aflatoxins } \\
\text { concentration }\end{array}$} & \multicolumn{2}{|c|}{$\begin{array}{l}\text { Aspergillus section } \\
\text { Flavi density }\end{array}$} \\
\hline & $\begin{array}{l}\text { HPLC } \\
\text { (ng/ml) }\end{array}$ & $\begin{array}{l}\text { Duplex RT-PCR } \\
\text { (ng/ml) }\end{array}$ & $\begin{array}{l}\text { Plating counts } \\
\text { (Log cfu/g) }\end{array}$ & $\begin{array}{c}\text { Duplex RT-PCR } \\
\text { (Log spores/g) }\end{array}$ \\
\hline 1 & aND & 0.53 & ND & $N D$ \\
\hline 2 & ND & $N D$ & 2.67 & 3.63 \\
\hline 3 & $N D$ & $N D$ & ND & $N D$ \\
\hline 4 & $N D$ & ND & 2.23 & 3.29 \\
\hline 5 & $N D$ & 0.45 & 3.00 & 3.76 \\
\hline 6 & 114 & 106 & 6.28 & 6.75 \\
\hline 7 & 53.6 & 46.2 & 6.94 & 7.33 \\
\hline 8 & 198 & 185 & 6.98 & 7.55 \\
\hline 9 & 111 & 110 & 7.01 & 7.66 \\
\hline 10 & 32.0 & 25.9 & 6.86 & 7.61 \\
\hline 11 & 57.2 & 47.4 & 6.88 & 7.66 \\
\hline 12 & 70.7 & 66.7 & 6.88 & 7.58 \\
\hline 13 & 177 & 169 & 7.12 & 8.29 \\
\hline 14 & 143 & 127 & 7.15 & 8.25 \\
\hline 15 & 651 & 640 & 7.19 & 8.28 \\
\hline 16 & 241 & 233 & 6.51 & 7.03 \\
\hline 17 & 269 & 237 & 6.73 & 7.10 \\
\hline 18 & 261 & 241 & 7.02 & 7.73 \\
\hline 19 & 308 & 288 & 6.93 & 7.22 \\
\hline 20 & 337 & 321 & 7.38 & 8.65 \\
\hline 21 & 318 & 314 & 6.61 & 7.25 \\
\hline 22 & 5.19 & 6.13 & 4.74 & 5.74 \\
\hline 23 & 36.2 & 38.2 & 5.10 & 5.90 \\
\hline 24 & 556 & 524 & 5.67 & 6.39 \\
\hline 25 & 980 & 965 & 7.25 & 8.40 \\
\hline
\end{tabular}

${ }^{a} N D$, not detectable. All assays were carried out in five replicates.

agreement, with a linear regression equation: $y=1.06 x+0.38$ and $R^{2}=0.98$ (Figure 5).

\section{Application Prospect}

According to the sample analysis protocol, aflatoxins in maize samples were 21 -fold diluted, meaning the LOD, sensitivity, and linear range for total aflatoxin detection in maize were 0.42 , 5.25 , and $1.05-25.41 \mu \mathrm{g} / \mathrm{kg}$, respectively, and linear range for Aspergillus section Flavi detection was $8 \times 10^{2}$ to $8 \times 10^{8}$ spores/g. Additionally, approximately $2 \mathrm{~h}$ was needed for samples preparation, $4 \mathrm{~h}$ for the Section "Immunoreaction for Small Molecular Contaminant Detection," $4 \mathrm{~h}$ for the Section "Isolation of DNA from Maize Samples," and $1 \mathrm{~h}$ for the analysis using realtime PCR instrument. Therefore, approximately $11 \mathrm{~h}$ was enough for the whole detection period.

With all of the above performance, this newly developed method was a good demonstration for simultaneous detection of small molecular contaminants and microorganisms in agrofoods. Generally, if nanobody phages specific for small molecular contaminants are available, the simultaneous detection would become not a challenge. Currently, nanobody phages specific
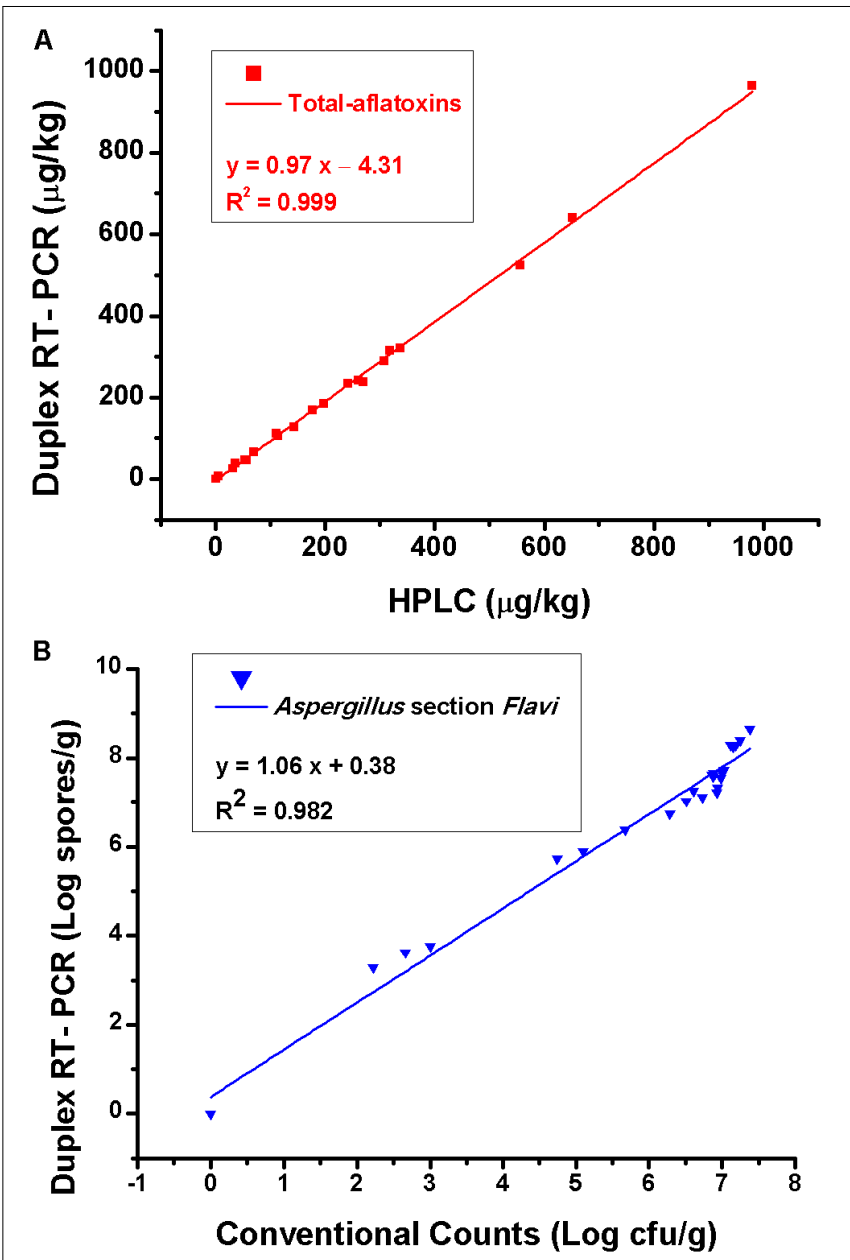

FIGURE 5 | (A) Correlation of total aflatoxins results obtained by the duplex real-time PCR and HPLC and (B) results of Aspergillus section Flavi obtained by the duplex real-time PCR and conventional plating counts. Each data point is the average of five independent measurements.

for various contaminants such as zearalenone (Wang et al., 2016), ochratoxin A (Liu et al., 2014), deoxynivalenol (Tu et al., 2012), fumonisin $B_{1}$ (Shu et al., 2019), synthetic microorganics (Wang et al., 2013a; Hua et al., 2015; Ding et al., 2017), citrinin (CIT) (Xu et al., 2015), and microcystins (MCs) (Xu et al., 2018) are available. Therefore, using the new method developed here, the simultaneous detection for these small molecular contaminants and their related microorganisms could also be realized.

\section{CONCLUSION}

In order to provide an analytical technology to detect small molecular contaminants and microorganisms, the simultaneous detection of aflatoxins and its major fungi (Aspergillus flavus and $A$. parasiticus) in maize was developed as an example to demonstrate it. The entire process for the simultaneous detection requires less than 1 day, thus time saving compared 
with separate detections. Importantly, this technical platform not only achieved the goal of simultaneous quantifications but also satisfied technical features of high throughput, high sensitivity, and wider linear range. However, the tedious technical procedure might be considered as inefficiency at current stage, especially on the procedure of the DNA isolation. Therefore, simplifying protocols for samples preparation are necessary to be explored, further to save time and improve work efficiency. Overall, this detection platform had a great potential for simultaneous detection of small molecular contaminants and microorganisms, which could, in a significant measure, advance new ideas for the development of detection technologies.

\section{DATA AVAILABILITY STATEMENT}

The datasets generated for this study are available on request to the corresponding author.

\section{REFERENCES}

Bagheri, H., Yamini, Y., Safari, M., Asiabi, H., Karimi, M., and Heydari, A. (2016). Simultaneous determination of pyrethroids residues in fruit and vegetable samples via supercritical fluid extraction coupled with magnetic solid phase extraction followed by HPLC-UV. J. Supercrit. Fluids 107, 571-580. doi: 10. 1016/j.supflu.2015.07.017

Bagnara, A., Mayer, Z., and Geisen, R. J. M. R. (2000). Quantification of Aspergiullus flavus BFE96 by sybr green Q-PCR in black pepper. Mycotoxin Res. 16, 244-247. doi: 10.1007/BF02940049

Bennett, J. W., and Klich, M. (2003). Mycotoxins. Clin. Microbiol. Rev. 16, 497-516. doi: $10.1128 / \mathrm{cmr} \cdot 16.3 .497-516.2003$

Dasenaki, M. E., Michali, C. S., and Thomaidis, N. S. (2016). Analysis of 76 veterinary pharmaceuticals from 13 classes including aminoglycosides in bovine muscle by hydrophilic interaction liquid chromatography-tandem mass spectrometry. J. Chromatogr. A 1452, 67-80. doi: 10.1016/j.chroma.2016.05.031

Desjardins, A. (2003). Mycotoxins: risks in plant, animal, and human systems. J. AAHE-ERIC/High. Educ. Res. Rep. 9, 48-50.

Ding, Y., Hua, X., Sun, N., Yang, J., Deng, J., Shi, H., et al. (2017). Development of a phage chemiluminescent enzyme immunoassay with high sensitivity for the determination of imidaclothiz in agricultural and environmental samples. Sci. Total Environ. 609, 854-860. doi: 10.1016/j.scitotenv.2017.07.214

Eaton, D. L., and Gallagher, E. P. (1994). Mechanisms of aflatoxin carcinogenesis. Annu. Rev. Pharmacol. Toxicol. 34, 135-172.

Geisen, R. (1996). Multiplex Polymerase Chain Reaction for the Detection of Potential Aflatoxin and Sterigmatocystin Producing Fungi. Syst. Appl. Microbiol. 19, 388-392. doi: 10.1016/s0723-2020(96)80067-1

Giorni, P., Magan, N., Pietri, A., Bertuzzi, T., and Battilani, P. (2007). Studies on Aspergillus section Flavi isolated from maize in northern Italy. Int J Food Microbiol 113, 330-338. doi: 10.1016/j.ijfoodmicro.2006.09.007

Gourama, H., and Bullerman, L. B. (1995). Aspergillus flavus and Aspergillus parasiticus: aflatoxigenic fungi of concern in foods and feeds: a review. J. Food Prot. 58, 1395-1404. doi: 10.4315/0362-028x-58.12.1395

Hanna, S. E., Connor, C. J., and Wang, H. H. (2005). Real-time polymerase chain reaction for the food microbiologist: technologies, applications, and limitations. J. Food Sci. 70, R49-R53.

Hua, X., Zhou, L., Feng, L., Ding, Y., Shi, H., Wang, L., et al. (2015). Competitive and noncompetitive phage immunoassays for the determination of benzothiostrobin. Anal. Chim. Acta 890, 150-156. doi: 10.1016/j.aca.2015. 07.056

Iheanacho, H. E., Dutton, M. F., Steenkamp, P. A., Steenkamp, L., Makun, H. A., Swart, A., et al. (2014). Real time PCR of Nor 1 (aflD) gene of aflatoxin producing fungi and its correlative quantization to aflatoxin levels in

\section{AUTHOR CONTRIBUTIONS}

$\mathrm{PL}$ and $\mathrm{QZ}$ conceived the research and acquired the funding. QZ, PL, and XR designed the experiments and analyzed the data. The manuscript was written through contributions of all authors. All authors have given approval to the final version of the manuscript.

\section{FUNDING}

This work was supported by the National Key Research and Development Program of China (2016YFE0206500), the National Natural Science Foundation of China (31801665), the Major Project of Hubei Provincial Technical Innovation (2018ABA081), and the Agricultural Science and Technology Innovation Program of CAAS (CAAS-XTCX2019024).

South African compound feeds. J. Microbiol. Methods 97, 63-67. doi: 10.1016/j. mimet.2013.12.014

Jennings, D. H., and Lysek, G. (1996). Fungal Biology: Understanding The Fungal Lifestyle. Milton Park: BIOS Scientific Publishers.

Kaminskyj, S. G. W., and Hamer, J. E. (1998). hyp loci control cell pattern formation in the vegetative mycelium of Aspergillus nidulans. Genetics 148, 669-680.

Kensler, T. W., Roebuck, B. D., Wogan, G. N., and Groopman, J. D. (2011). Aflatoxin: a 50-Year Odyssey of Mechanistic and Translational Toxicology. Toxicol. Sci. 120(Suppl. 1), S28-S48. doi: 10.1093/toxsci/kfq283

Khayoon, W. S., Saad, B., Yan, C. B., Hashim, N. H., Ali, A. S. M., Salleh, M. I., et al. (2010). Determination of aflatoxins in animal feeds by HPLC with multifunctional column clean-up. Food Chem. 118, 882-886. doi: 10.1016/j. foodchem.2009.05.082

Klich, M. A. (2007). Aspergillus flavus: the major producer of aflatoxin. Mol. Plant Pathol. 8, 713-722. doi: 10.1111/j.1364-3703.2007.00436.x

Leber, A. L., Everhart, K., Balada-Llasat, J. M., Cullison, J., Daly, J., Holt, S., et al. (2016). Multicenter Evaluation of BioFire FilmArray Meningitis/Encephalitis Panel for Detection of Bacteria, Viruses, and Yeast in Cerebrospinal Fluid Specimens. J. Clin. Microbiol. 54, 2251-2261. doi: 10.1128/JCM.00730-16

Lei, J., Li, P., Zhang, Q., Wang, Y., Zhang, Z., Ding, X., et al. (2014). Antiidiotypic nanobody-phage based real-time immuno-PCR for detection of hepatocarcinogen aflatoxin in grains and feedstuffs. Anal. Chem. 86, 1084110846. doi: 10.1021/ac5029424

Li, H., Xin, H., and Li, S. F. (2015). Multiplex PMA-qPCR Assay with Internal Amplification Control for Simultaneous Detection of Viable Legionella pneumophila, Salmonella typhimurium, and Staphylococcus aureus in Environmental Waters. Environ. Sci. Technol. 49, 14249-14256. doi: 10.1021/ acs.est.5b03583

Li, J., Yan, H., Tan, X., Lu, Z., and Han, H. (2019). Cauliflower-Inspired 3D SERS Substrate for Multiple Mycotoxins Detection. Anal. Chem. 91, 3885-3892. doi: 10.1021/acs.analchem.8b04622

Li, X., Li, P., Zhang, Q., Li, R., Zhang, W., Zhang, Z., et al. (2013). Multi-component immunochromatographic assay for simultaneous detection of aflatoxin $B_{1}$, ochratoxin A and zearalenone in agro-food. Biosens. Bioelectron. 49, 426-432. doi: 10.1016/j.bios.2013.05.039

Liu, X., Xu, Y., Xiong, Y. H., Tu, Z., Li, Y. P., He, Z. Y., et al. (2014). VHH phage-based competitive real-time immuno-polymerase chain reaction for ultrasensitive detection of ochratoxin A in cereal. Anal. Chem. 86, 7471-7477. doi: $10.1021 /$ ac501202d

Mayer, Z., Bagnara, A., Farber, P., and Geisen, R. (2003a). Quantification of the copy number of nor-1, a gene of the aflatoxin biosynthetic pathway by real-time PCR, and its correlation to the cfu of Aspergillus flavus in foods. Int. J. Food Microbiol. 82, 143-151. doi: 10.1016/s0168-1605(02)00250-7 
Mayer, Z., Farber, P., and Geisen, R. (2003b). Monitoring the production of aflatoxin B-1 in wheat by measuring the concentration of nor-1 mRNA. Appl. Environ. Microbiol. 69, 1154-1158. doi: 10.1128/aem.69.2.1154-1158.2003

Passone, M. A., Rosso, L. C., Ciancio, A., and Etcheverry, M. (2010). Detection and quantification of Aspergillus section Flavi spp. in stored peanuts by real-time PCR of nor-1 gene, and effects of storage conditions on aflatoxin production. Int. J. Food Microbiol. 138, 276-281. doi: 10.1016/j.ijfoodmicro.2010.01.003

Playford, E. G., Kong, F., Sun, Y., Wang, H., Halliday, C., and Sorrell, T. C. (2006). Simultaneous detection and identification of Candida, Aspergillus, and Cryptococcus species by reverse line blot hybridization. J. Clin. Microbiol. 44, 876-880. doi: 10.1128/JCM.44.3.876-880.2006

Priyanka, S. R., Venkataramana, M., Balakrishna, K., Murali, H. S., and Batra, H. V. (2015). Development and evaluation of a multiplex PCR assay for simultaneous detection of major mycotoxigenic fungi from cereals. J. Food Sci. Technology-Mysore 52, 486-492. doi: 10.1007/s13197-013-1001-3

Rahn, S., Schuck, A., Kondakci, M., Haas, R., Neuhausen, N., Pfeffer, K., et al. (2016). A novel comprehensive set of fungal Real time PCR assays (fuPCR) for the detection of fungi in immunocompromised haematological patients-A pilot study. Int. J. Med. Microbiol. 306, 611-623. doi: 10.1016/j.ijmm.2016.10.003

Reddy, K. R. N., Salleh, B., Saad, B., Abbas, H. K., Abel, C. A., and Shier, W. T. (2010). An overview of mycotoxin contamination in foods and its implications for human health. Toxin Rev. 29, 3-26. doi: 10.3109/15569541003598553

Ren, X., Zhang, Q., Wu, W., Yan, T., Tang, X., Zhang, W., et al. (2019). Anti-idiotypic nanobody-phage display-mediated real-time immuno-PCR for sensitive, simultaneous and quantitative detection of total aflatoxins and zearalenone in grains. Food Chem. 297, 124912. doi: 10.1016/j.foodchem.2019. 05.186

Rodriguez, A., Rodriguez, M., Luque, M. I., Martin, A., and Cordoba, J. J. (2012). Real-time PCR assays for detection and quantification of aflatoxinproducing molds in foods. Food Microbiol. 31, 89-99. doi: 10.1016/j.fm.2012. 02.009

Shu, M., Xu, Y., Dong, J.-X., Zhong, C., Hammock, B. D., Wang, W.-J., et al. (2019). Development of a noncompetitive idiometric nanobodies phage immumoassay for the determination of fumonisin B-1. Food Agric. Immunol. 30, 510-521. doi: 10.1080/09540105.2019.1604637

Svec, D., Tichopad, A., Novosadova, V., Pfaffl, M. W., and Kubista, M. (2015). How good is a PCR efficiency estimate: recommendations for precise and robust qPCR efficiency assessments. Biomol. Detect. Quantif. 3, 9-16. doi: 10.1016/j. bdq.2015.01.005

Taranova, N. A., Berlina, A. N., Zherdev, A. V., and Dzantiev, B. B. (2015). 'Traffic light' immunochromatographic test based on multicolor quantum dots for the simultaneous detection of several antibiotics in milk. Biosens. Bioelectron. 63, 255-261. doi: 10.1016/j.bios.2014.07.049

Trail, F., Chang, P. K., Cary, J., and Linz, J. E. (1994). Structural and functional analysis of the nor-1 gene involved in the biosynthesis of aflatoxins by Aspergillus parasiticus. Appl. Environ. Microbiol. 60, 4078-4085. doi: 10.1128/ aem.60.11.4078-4085.1994

Tu, Z., Xu, Y., He, Q. H., Fu, J. H., Liu, X., and Tao, Y. (2012). Isolation and characterisation of deoxynivalenol affinity binders from a phage display library based on single-domain camelid heavy chain antibodies (VHHs). Food Agric. Immunol. 23, 123-131. doi: 10.1080/09540105.2011.606560

Vaisocherova-Lisalova, H., Visova, I., Ermini, M. L., Springer, T., Song, X. C., Mrazek, J., et al. (2016). Low-fouling surface plasmon resonance biosensor for multi-step detection of foodborne bacterial pathogens in complex food samples. Biosens. Bioelectron. 80, 84-90. doi: 10.1016/j.bios.2016.01.040

Varga, J., Frisvad, J. C., and Samson, R. A. (2011). Two new aflatoxin producing species, and an overview of Aspergillus section Flavi. Stud. Mycol. 69, 57-80. doi: 10.3114/sim.2011.69.05

Wang, C., Qian, J., An, K., Huang, X., Zhao, L., Liu, Q., et al. (2017a). Magneto-controlled aptasensor for simultaneous electrochemical detection of dual mycotoxins in maize using metal sulfide quantum dots coated silica as labels. Biosens. Bioelectron. 89(Pt 2), 802-809. doi: 10.1016/j.bios.2016. 10.010

Wang, P., Wu, L., Lu, Z., Li, Q., Yin, W., Ding, F., et al. (2017b). Gecko-Inspired Nanotentacle Surface-Enhanced Raman Spectroscopy Substrate for Sampling and Reliable Detection of Pesticide Residues in Fruits and Vegetables. Anal. Chem. 89, 2424-2431. doi: 10.1021/acs.analchem.6b04324

Wang, J., Liu, Z. P., Li, G. Q., Li, J., Kim, H. J., Shelver, W. L., et al. (2013a). Simultaneous development of both competitive and noncompetitive immunoassays for 2,2', 4,4'-tetrabromodiphenyl ether using phage-displayed peptides. Anal. Bioanal. Chem. 405, 9579-9583. doi: 10.1007/s00216-0137364-5

Wang, Y., Li, P., Majkova, Z., Bever, C. R., Kim, H. J., Zhang, Q., et al. (2013b). Isolation of alpaca anti-idiotypic heavy-chain single-domain antibody for the aflatoxin immunoassay. Anal. Chem. 85, 8298-8303. doi: 10.1021/ac4015885

Wang, X., He, Q., Xu, Y., Liu, X., Shu, M., Tu, Z., et al. (2016). Anti-idiotypic VHH phage display-mediated immuno-PCR for ultrasensitive determination of mycotoxin zearalenone in cereals. Talanta 147, 410-415. doi: 10.1016/j.talanta. 2015.09.072

Wang, Y., Liu, N., Ning, B., Liu, M., Lv, Z., Sun, Z., et al. (2012). Simultaneous and rapid detection of six different mycotoxins using an immunochip. Biosens. Bioelectron. 34, 44-50. doi: 10.1016/j.bios.2011.12.057

Wilson, I. G. (1997). Inhibition and facilitation of nucleic acid amplification. Appl. Environ. Microbiol. 63, 3741-3751. doi: 10.1128/aem.63.10.3741-3751.1997

Xu, C., Yang, Y., Liu, L., Li, J., Liu, X., Zhang, X., et al. (2018). Microcystin-LR nanobody screening from an alpaca phage display nanobody library and its expression and application. Ecotoxicol. Environ. Saf. 151, 220-227. doi: 10.1016/ j.ecoenv.2018.01.003

Xu, Y., Xiong, L., Li, Y., Xiong, Y., Tu, Z., Fu, J., et al. (2015). Citrinin detection using phage-displayed anti-idiotypic single-domain antibody for antigen mimicry. Food Chem. 177, 97-101. doi: 10.1016/j.foodchem.2015. 01.007

Yoo, S. M., Kim, D. K., and Lee, S. Y. (2015). Aptamer-functionalized localized surface plasmon resonance sensor for the multiplexed detection of different bacterial species. Talanta 132, 112-117. doi: 10.1016/j.talanta.2014.09.003

Zhang, D., Li, P., Zhang, Q., Zhang, W., Huang, Y., Ding, X., et al. (2009). Production of ultrasensitive generic monoclonal antibodies against major aflatoxins using a modified two-step screening procedure. Anal. Chim. Acta 636, 63-69. doi: 10.1016/j.aca.2009.01.010

Zhang, Z., Hu, X., Zhang, Q., and Li, P. (2016). Determination for multiple mycotoxins in agricultural products using HPLC-MS/MS via a multiple antibody immunoaffinity column. J. Chromatogr. B Analyt. Technol. Biomed. Life Sci. 1021, 145-152. doi: 10.1016/j.jchromb.2016.02.035

Zhou, R., and Linz, J. E. (1999). Enzymatic function of the nor-1 protein in aflatoxin biosynthesis in Aspergillus parasiticus. Appl. Environ. Microbiol. 65, 5639-5641. doi: 10.1128/aem.65.12.5639-5641.1999

Zhu, W. X., Yang, J. Z., Wang, Z. X., Wang, C. J., Liu, Y. F., and Zhang, L. (2016). Rapid determination of 88 veterinary drug residues in milk using automated TurborFlow online clean-up mode coupled to liquid chromatography-tandem mass spectrometry. Talanta 148, 401-411. doi: 10.1016/j.talanta.2015.10.037

Conflict of Interest: The authors declare that the research was conducted in the absence of any commercial or financial relationships that could be construed as a potential conflict of interest.

Copyright (c) 2020 Ren, Yue, Mwakinyali, Zhang, Zhang and Li. This is an openaccess article distributed under the terms of the Creative Commons Attribution License (CC BY). The use, distribution or reproduction in other forums is permitted, provided the original author(s) and the copyright owner(s) are credited and that the original publication in this journal is cited, in accordance with accepted academic practice. No use, distribution or reproduction is permitted which does not comply with these terms. 